\title{
Increased Rural Connectivity and its Effects on Health Outcomes
}

\section{Hadia Majid ${ }^{*}$}

\begin{abstract}
This paper examines the effects of increased connectivity in rural areas on child health outcomes. In particular, it studies whether improved access to markets for rural areas through an upgraded road network and greater openness, as measured by village electrification status, has had a positive impact on child health outcomes and awareness of health practices such as immunization and prenatal care. Using a 16-year panel dataset from rural Pakistan, we estimate two iterations of a probit model, where one examines the probability of child $i$ being vaccinated and the second estimates the incidence of use of prenatal care. The results support the hypothesis that greater connectivity, as measured by road connectivity and electrification, improves health outcomes by increasing the likelihood of immunization and uptake of prenatal care.
\end{abstract}

Keywords: Child immunization, prenatal care, access to markets, electrification, rural Pakistan.

JEL classification: I10.

\section{Introduction}

This paper explores the impact of increased connectivity in rural areas to the outside world, on child health outcomes. It focuses on rural Pakistan, with outcomes examined over a 16-year period. In particular, we study whether rural areas' improved access to markets through an upgraded road network and greater openness-as measured by village electrification status - has had a positive impact on child health outcomes and awareness of health practices such as immunization and prenatal care.

The focus on child immunization and prenatal care is driven not only by their significant and positive effect on health in adulthood, but also by the importance of prenatal care in the prevention of maternal and infant deaths. Women who seek prenatal care are found to be more likely to select a trained attendant at birth and, while there is some but no conclusive

\footnotetext{
* Assistant Professor, Department of Economics, Lahore University of Management Sciences, Pakistan.
} 
evidence to show that the use of skilled attendants reduces maternal deaths, trained birth attendants have been found to be effective in reducing newborn mortality (Bloom, Lippeveld, \& Wypij, 1999; Sibley, Sipe, Brown, Diallo, McNatt, \& Habarta, 2007).

There is a considerable body of literature that highlights the role of health status in early life on health as well as economic outcomes in adulthood. Immunization directly affects child and adult disease burden, while the mother's use of prenatal care affects in utero and infancy nutritional status, which may affect chronic disease burden in later life (Alexander \& Korenbrot, 1995; Case \& Paxson, 2008). Moreover, childhood health and related outcomes have been found to exert significant influence on economic outcomes, and explain a large fraction of the variance in employment and social status in adulthood (Case, Fertig, \& Paxson, 2005).

Particularly with regard to Pakistan, the incidence of under-five deaths is especially high (87 per 1,000 live births), and the United Nations Children's Fund (UNICEF) (2008) reports that one third of these deaths are attributable to vaccine-preventable diseases. Moreover, 20 percent of the disease burden of children under five is related to poor maternal health and nutrition during pregnancy (UNICEF, 2008). If we consider immunization coverage, we find that one in every five children is not immunized; in many rural areas, two out of every three children are not immunized (United States Agency for International Development, 2012). Thus, the factors affecting the incidence of immunization and use of prenatal care are likely to have a significant impact both on child and lifelong health outcomes as well as on economic and employment opportunities. This makes studying these variables especially relevant for policy interventions aimed at improving human capital accumulation and economic growth.

The literature on health outcomes studies both demand- and supply-side factors that affect health status. With regard to the former, Alderman and Gertler's (1997) model provides insight into why parental preferences may be biased toward the son: parents are more likely to invest in the human capital of their sons than that of their daughters when the market returns on such an investment are higher. Similarly, Ensor and Cooper (2004) carry out an extensive study of the barriers influencing obstetric choices in Bangladesh. They find that demand-side factors such as knowledge of (health) issues, mobility checks, and monetary considerations are the most commonly cited reasons for poor access to health services. 
With regard to the effect of supply-side factors on health outcomes, Haddad and Hoddinott (1994) find that distance to health facilities has a negative effect on health outcomes for both boys and girls in Côte d'Ivoire. In the same vein, Holmes (2006), in a study on rural Pakistan, shows that community prices, along with infrastructure such as the availability of piped water, distance to the nearest shops and public health clinics, and the quality of the closest health facilities, all play a significant role in reducing gender gaps in health outcomes.

Although considerable work has been done on the effect of community and health infrastructure variables on health outcomes, most studies have generally focused on either factors related to distance or to the quality of public health clinics (where the supply of doctors, nurses, and pharmaceuticals is also considered). To my knowledge, no study has as yet examined the effects of increased openness on rural health outcomes. Thus, I use electrification status and the state of the road network in rural Pakistan as a proxy for openness and increased market accessibility.

It is worth noting that, while the road network determines ease of travel to and from a village-thus increasing openness-electrification allows villagers to access information, connecting them to the outside world regardless of road conditions. ${ }^{1}$ The main hypothesis is that, as villages become less remote, the access of residents to (health) information as well as general goods and services improves, which, in turn, reflects in child immunization status and the use of prenatal care.

Using a 16-year panel dataset for rural Pakistan, I estimate two iterations of a probit model: one examines the probability of child $i$ being vaccinated, and the second estimates the incidence of use of prenatal care. The results support the hypothesis that greater connectivity, as measured by road connectivity and electrification, improves health outcomes by increasing the likelihood of immunization and uptake of prenatal care.

The rest of the paper is organized as follows: Section 2 describes the data and sets up the econometric methodology. Section 3 discusses the results and policy implications, and Section 4 concludes the study.

\footnotetext{
${ }^{1}$ In rural Pakistan, it is common practice for villagers to congregate at a neighbor's house or central shop to watch television. Hence, even those households that do not own a television set may be able to consume television programming as long as the village is electrified.
} 


\section{Data}

This paper uses a panel dataset developed by the International Food Policy Research Institute (IFPRI) and the Pakistan Institute of Development Economics (PIDE). IFPRI conducted 12 rounds of the Pakistan Panel Survey (PPS) between July 1986 and September 1991. This survey was carried out at the household level for districts of three provinces-Sindh, Punjab, and Khyber Pakhtunkhwa-and spanned approximately 900 rural households. Starting in 2001, PIDE resumed the IFPRI panel with the Pakistan Rural Household Survey (PRHS), which includes 60 percent of the original IFPRI sample and was conducted in Sindh and Punjab. To date, three rounds of the PRHS have been performed: the first in 2001/02, the second in 2003/04, and the third in 2009/10 (which is not yet publicly available).

I create my panel using the 2001/02 round of the PIDE follow-up data and the 1986-91 round of the IFPRI data. The PRHS was also conducted at the household level and, like the IFPRI data, contains community-level variables including information on roads leading into the village, the status of health facilities, and incidence of immunization and prenatal care. Using the PPS and PRHS, I trace the evolution of the road and electricity network along with the health infrastructure and health outcomes for specific villages in Sindh and Punjab over a 16-year period.

Table 1 summarizes key statistics for the dataset. In terms of the accessibility of health facilities and connectivity, the table shows an improvement from 1986-91 to 2001/02. The percentage of children ever vaccinated and the percentage of women receiving prenatal care also improves from 1986-91 to 2001/02. 
Table 1: Summary statistics

\begin{tabular}{lcc}
\hline Variable & 1986-91 round & 2001/02 round \\
\hline & Village statistics & \\
Percent with paved roads & 25.0 & 63.0 \\
Percent with electricity & 53.5 & 83.0 \\
Percent with any health facility & 5.9 & 23.0 \\
Mean distance between village and any & $5.16 \mathrm{~km}$ & $3.5 \mathrm{~km}$ \\
health facility & \multicolumn{3}{|c}{} \\
\hline & Household characteristics \\
Percent of children ever vaccinated & 47.0 & 71.0 \\
$\quad$ Male & 48.0 & 69.0 \\
Percent of women receiving prenatal care & 10.7 & 50.0 \\
Total (no. of households) & 998.0 & 908.0 \\
\hline
\end{tabular}

\subsection{Econometric Methodology}

A difference-in-difference approach would have been ideal to isolate the causal effect of road improvements and electrification on health outcomes. However, the PRHS does not follow all individuals who were covered in the PPS. Also, there is a 10-year gap between the last PPS round and the first PRHS round, which is likely to have a significant effect on the demographic make-up of each surveyed village. My analysis focuses, therefore, on isolating how a community's access to roads and electricity has affected the wellbeing of individuals, especially children, in the village. The basic probit regression is provided in (1).

$$
h_{i, j}=\alpha_{0}+\Psi R+\Theta F+\Pi E+\Phi X_{i j}+\varepsilon_{i j}
$$

where $h_{i, j}$ represents the health outcomes of child $i$ in family $j$ in the PRHS round. I estimate two iterations of (1) with $h_{i, j}$ varying from whether the child was immunized to whether the mother received prenatal care when pregnant with child $i$.

$\varepsilon_{i j}$ is a random, idiosyncratic error term. $R$ is a vector that measures the strength of the road network, in particular categorizing if the village has a road connecting it to a market and whether that road has improved in the 16-year period covered in the panel. $E$ specifies the electrification status of the village, measuring it in 2001/02 relative to 1986-91. $F$ is a vector representing community-level variables, especially those related to the health infrastructure; $X_{i j}$ is a vector of family and child characteristics, 
including age, family size, and education levels. Household wealth status is represented by a wealth index that uses productive assets such as agricultural assets, along with information on ownership of livestock and household durables. In order to distinguish between the poor and middleincome strata more exactly, I also include information on the structure of the dwelling (mud, semi-permanent, or permanent).

I use principal components analysis (PCA) to determine the weights of the wealth index. By applying PCA to a set of variables, I can extract orthogonal linear combinations of the variables that capture common information most successfully (see Filmer \& Pritchett, 2001). The first principal component, expressed in terms of the original $(M)$ variables is, therefore, an index for each household:

$$
A_{1 h}=f_{11} \times \frac{v_{1, h} \bar{v}_{1}}{s d_{1}}+\cdots+f_{1 M} \times \frac{v_{M, h}-\overline{v_{M}}}{s d_{M}}
$$

The procedure first standardizes the variables using their mean $(\bar{v})$ and standard deviation ( $s d)$, and then calculates the "scoring factors $(f)$. ." Finally, for each household, the variable values are multiplied by the scores and summed for the wealth index. All households are sorted by the index and cut-off values established for percentiles of the population. Households are assigned to groups based on their value of the index. I use similar cutoffs to those in Filmer and Pritchett (2001) and Vyas and Kumaranayake (2006): the bottom 40 percent is referred to as "poor," the next 40 percent as "middle," and the top 20 percent as "rich."

\section{Results}

Table 2 lists the results of the probit regressions. The analysis considers two dependent variables:

1. Whether the child has ever been vaccinated (as recorded in the 2001/02 round): Immune_01

2. Whether the mother received prenatal care when pregnant with child $i$ (as recorded in the 2001/02 round): Pre-natal

The main variables of interest include those that proxy village connectivity or openness as measured by electrification status and by the condition of the road leading to the nearest large market. These variables have been constructed such that they measure the status of the proxy in 2001/02 relative to 1986-91. Thus, four electrification dummy variables are created: (i) Electri: '01 not '86, which takes a value of 1 if the village had an 
electric grid in 2001 but not in 1986, and 0 otherwise; (ii) Elect: Both, which takes a value of 1 if the village was electrified in both rounds; and (iii) Elect: Never, which takes a value of 1 if the village was never electrified.

It is worth noting that, for approximately 10 percent of villages, the data shows the presence of an electric grid in 1986-91 but not in 2001/02, which serves as the base category for both regression analyses. Similarly, road_improve takes a value of 1 if the condition of the road leading to the market is reported as having improved from 1986 to 2001; road_worsen takes a value of 1 if the road leading to the market has worsened from 1986 to 2001; and no_road_both takes a value of 1 if the village did not have a road to the market in either round.

Compared to villages that lost their electric grid between 1986-91 and 2001/02, villages that had electricity in 2001 (only) and those that had electricity in both rounds, see a positive and significant effect on the incidence of prenatal care, with the effect of electricity in both rounds being significantly greater than that in only one round. Moreover, improved connectivity to the market also has a positive and significant effect on the incidence of prenatal care. With regard to the likelihood of being vaccinated, villages that were electrified in 1986 but not in 2001 are the worst off. Here, too, we find that having electricity in both rounds has a significantly larger effect on the likelihood of being immunized.

While road conditions have no significant effect on the likelihood of immunization, the larger the proportion of children vaccinated in 1986-91, the greater the chances that a child was vaccinated in 2001 . This is best understood by considering that those villages that have already seen large numbers of children vaccinated are more likely to be aware of the advantages of immunization, and so are more likely to engage in this in later years as well. The effects of road connectivity, electrification, and the proportion of children vaccinated in 1986 support the primary hypothesis that reduction in remoteness has a positive effect on health outcomes. Indeed, as villages become more connected (as measured by electrification and roads) and more aware of the benefits of certain health practices (which prop_vaccin_86 helps capture), the likelihood that children are immunized and mothers seek prenatal care, increases. 
Table 2: Probit regression results

\begin{tabular}{|c|c|c|}
\hline & $\begin{array}{c}\text { (1) } \\
\text { Immun_01 }\end{array}$ & $\begin{array}{c}\text { (2) } \\
\text { Prenatal }\end{array}$ \\
\hline \multirow[t]{2}{*}{ Electr: Never } & 0.688 & -0.014 \\
\hline & $(0.079)^{* *}$ & $(0.025)$ \\
\hline \multirow[t]{2}{*}{ Electr: '01 not '86 } & 0.726 & 0.093 \\
\hline & $(0.101)^{* *}$ & $(0.025)^{* *}$ \\
\hline \multirow[t]{2}{*}{ Electr: Both } & 0.997 & 0.427 \\
\hline & $(0.002)^{* *}$ & $(0.027)^{* *}$ \\
\hline \multirow[t]{2}{*}{ road_improve } & -0.038 & 0.044 \\
\hline & $(0.020)$ & $(0.018)^{*}$ \\
\hline \multirow[t]{2}{*}{ no_road_both } & 0.041 & \\
\hline & $(0.020)$ & \\
\hline \multirow[t]{2}{*}{ road_worsen } & & -0.143 \\
\hline & & $(0.066)^{*}$ \\
\hline \multirow[t]{2}{*}{ health_in_01 } & -0.003 & 0.148 \\
\hline & $(0.003)$ & $(0.010)^{* *}$ \\
\hline \multirow[t]{2}{*}{ prop_vaccin_86 } & 0.376 & \\
\hline & $(0.021)^{* *}$ & \\
\hline \multirow[t]{2}{*}{ Middle } & 0.185 & 0.264 \\
\hline & $(0.014)^{* *}$ & $(0.012)^{* *}$ \\
\hline \multirow[t]{2}{*}{ Rich } & 0.072 & 0.220 \\
\hline & $(0.006)^{* *}$ & $(0.013)^{* *}$ \\
\hline \multirow[t]{2}{*}{ tot_family_size } & -0.006 & -0.001 \\
\hline & $(0.001)^{* *}$ & $(0.001)$ \\
\hline \multirow[t]{2}{*}{ Gender } & 0.032 & 0.064 \\
\hline & $(0.003)^{* *}$ & $(0.010)^{* *}$ \\
\hline \multirow[t]{2}{*}{ mom_educ } & 0.008 & 0.023 \\
\hline & $(0.001)^{* *}$ & $(0.002)^{* *}$ \\
\hline \multirow[t]{2}{*}{ dad_educ } & -0.004 & -0.021 \\
\hline & $(0.001)^{* *}$ & $(0.001)^{* *}$ \\
\hline \multirow[t]{2}{*}{ mom_age } & -0.000 & -0.002 \\
\hline & $(0.000)^{* *}$ & $(0.000)^{* *}$ \\
\hline$N$ & 11,214 & 11,667 \\
\hline
\end{tabular}

Note: Robust standard errors in parentheses. ${ }^{*} p<0.05 ;{ }^{* *} p<0.01$. 
The regressions also control for the presence of an in-village health facility (in 2001), which has a positive effect on the incidence of prenatal care. Finally, compared to the lower-income strata, middle and rich classes are more likely to seek immunization and prenatal care for their children while boys are more likely to be immunized and their mothers to receive prenatal care.

\subsection{Policy Implications}

The results presented in this paper indicate that connectivity helps improve health outcomes. The results with respect to electrification may seem to point toward an expensive policy prescription, but it is worth noting that the Government of Pakistan already has a rural electrification program as well as a village electrification program in place. The former is especially geared toward those villages that are far from the national grid and so cannot be connected to it (see Pakistan, Alternative Energy Development Board, n.d.). Under this program, 3,000 homes in 49 villages in Sindh have been energized through solar energy, while under the latter about 850 electrification schemes have been approved and completed just by the Islamabad Electric Supply Company (IESCO) (see IESCO, n.d.). Thus, there is a concerted bid to extend the electric grid across Pakistan. ${ }^{2}$ This is unsurprising, especially when we consider that, while roads allow areas to be physically connected, electrification allows for greater access to information even in those areas that may be otherwise remote.

Furthermore, the positive effect of in-village health facilities on the probability of prenatal care and the positive effect of the proportion of children vaccinated in 1986 on the likelihood of immunization in 2001 points toward the importance of increasing the number of health units/clinics in rural areas and immunization drives to ensure that more children are vaccinated each year.

Some statistics on Pakistan's health service delivery and human resources are given in Table 3 below. These clearly show that the population's needs are far outmatched by the supply of healthcare. While the 2006-10 National Health Policy Guidelines include several welcome initiatives-such as the female ("lady") health worker community-based program that is geared toward bringing health information, some basic healthcare, and family planning services to women's doorsteps, and the involvement of multidonor-supported social protection programs-the

2 Since 1958, the total number of electrified villages has increased from 609 to 125,495 in February 2008 (see Water and Power Development Authority, n.d.). 
security issues surrounding immunization drives and the continual absence of provision of timely healthcare in rural areas point toward the need for more stringent and widespread reforms.

Table 3: Health facilities and human resource densities

\begin{tabular}{lrrr}
\hline Health human resources & $\mathbf{2 0 1 0 / 1 1}$ & $\mathbf{2 0 1 1 / 1 2}$ & $\mathbf{2 0 1 2 / 1 3}$ \\
\hline Registered doctors & 144,901 & 152,188 & 160,289 \\
Registered dentists & 10,508 & 11,584 & 12,544 \\
Registered nurses & 73,244 & 77,683 & 82,449 \\
Population per doctor & 1,222 & 1,164 & 1,127 \\
Population per dentist & 16,854 & 15,288 & 14,406 \\
Population per hospital bed & 1,701 & 1,647 & 1,786 \\
\hline
\end{tabular}

Source: Pakistan Economic Survey 2012-13: Health and Nutrition.

\section{Conclusion}

This paper has examined the effect of increased connectivity in rural areas on child health outcomes. In particular, it has studied whether rural areas' improved access to markets through an upgraded road network and greater openness-as measured by village electrification status-has a positive impact on child health outcomes and on awareness of health practices such as immunization and prenatal care.

Using a 16-year panel dataset on rural Pakistan, two iterations of a probit model were estimated: one examining the probability of child $i$ being vaccinated and the second estimating the incidence of use of prenatal care. The results support the hypothesis that greater connectivity, as measured by road connectivity and electrification, improves health outcomes by increasing the likelihood of immunization and uptake of prenatal care. Furthermore, the presence of in-village health facilities has a positive effect on the probability of prenatal care, while the proportion of children vaccinated in 1986 has a positive effect on the likelihood of immunization in 2001. 


\section{References}

Alderman, H., \& Gertler, P. (1997). Family resources and gender differences in human capital investments: The demand for children's medical care in Pakistan. In L. Haddad, J. Hoddinott, \& H. Alderman (Eds.), Intrahousehold resource allocation in developing countries: Models, methods, and policy. Baltimore, MD: Johns Hopkins University Press.

Alexander, G. R., \& Korenbrot, C. C. (1995). The role of prenatal care in preventing low birth weight. Future of Children, 5(1), 103-120.

Bloom, S. S., Lippeveld, T., \& Wypij, D. (1999). Does antenatal care make a difference to safe delivery? A study in urban Uttar Pradesh, India. Health Policy and Planning, 14(1), 38-48.

Case, A., Fertig, A., \& Paxson, C. (2005). The lasting impact of childhood health and circumstances. Journal of Health Economics, 24(2), 365389.

Case, A., \& Paxson, C. (2008). Stature and status: Height, ability, and labor market outcomes. Journal of Political Economy, 116, 499-532.

Ensor, T., \& Cooper, S. (2004). Overcoming barriers to health service access: Influencing the demand side. Health Policy and Planning, 19(2), 69-79.

Filmer, D., \& Pritchett, L. H. (2001). Estimating wealth effects without expenditure data-or tears: An application to educational enrollments in states of India. Demography, 38(1), 115-132.

Haddad, L., \& Hoddinott, J. (1994). Women's income and boy-girl anthropometric status in the Cote d'Ivoire. World Development, 22, 543-553.

Holmes, J. (2006). Do community factors have a differential impact on the health outcomes of boys and girls? Evidence from rural Pakistan. Health Policy and Planning, 21(3), 231-240.

Islamabad Electric Supply Company. (n.d.). Customer services. Retrieved from http://www.iesco.com.pk/index.php/customer-services/vielectrification.htm 
Pakistan, Alternative Energy Development Board. (n.d.). Rural electrification program. Retrieved from http:/ /www.aedb.org/rep.htm

Pakistan, Finance Division. (2013). Pakistan economic survey 2012-13. Islamabad, Pakistan: Author.

Pakistan, Water and Power Development Authority. (n.d.). Power wing development projects. Retrieved from http:/ / www.wapda.gov.pk/htmls/power-development.html

Sibley, L. M., Sipe, T. A., Brown, C. M., Diallo, M. M., McNatt, K., \& Habarta, N. (2007). Traditional birth attendant training for improving health behaviors and pregnancy outcomes (review). The Cochrane Library, 2, 1-47.

United Nations Children's Fund. (2008). The state of the world's children 2009: Maternal and newborn health. New York, NY: Author.

United States Agency for International Development. (2012). Childhood immunization in Pakistan (Research and Development Solutions Policy Brief No. 3). Washington, DC: Author.

Vyas, S., \& Kumaranayake, L. (2006). Constructing socioeconomic status indices: How to use principal component analysis. Health Policy and Planning, 21(6), 459-468. 